\title{
Health-Related Quality of Life of Coronary Artery Disease Patients under Secondary Prevention: A Cross-Sectional Survey from South India
}

\author{
Remya Sudevan, MBBS, MPH, PhD, ${ }^{1,2}$ Manu Raj, DNB, MS HRM, ${ }^{3}$ \\ Damodaran M.Vasudevan, MD, FRCP, HOD,${ }^{1}$ Rajesh Thachathodiyl, MD, DM-HOD, ${ }^{2}$ \\ Maniyal Vijayakumar, MD, DNB, DM, ${ }^{2}$ Jabir Abdullakutty, MD, DM, ${ }^{4}$ Paul Thomas, MD, DM, ${ }^{5}$ \\ Vijo George, MD, DM, ${ }^{5}$ Conrad Kabali, $\mathrm{PhD}^{6}$
}

\begin{abstract}
${ }^{1}$ Departments of Health Sciences Research, Amrita Institute of Medical Sciences \& Research Centre, Amrita Vishwa Vidyapeetham, Kochi, Kerala, India; ${ }^{2}$ Department of Cardiology, Amrita Institute of Medical Sciences \& Research Centre, Kochi, Kerala, India ${ }^{3}$ Department of Pediatric Cardiology \& Public Health Research, Amrita Institute of Medical Sciences \& Research Centre, Kochi, Kerala, India; ${ }^{4}$ Department of Cardiology, Lisie Hospital, Kochi, Kerala, India ${ }^{5}$ Ernakulam General Hospital, Ernakulam, Kerala, India; ${ }^{6}$ Department of Epidemiology, Dalla Lana School of Public Health, University of Toronto, Ontario, Canada
\end{abstract}

\section{ABSTRACT}

Background: Health-related quality of life (HRQOL) is emerging as an important outcome among patients with documented coronary artery disease (CAD). The primary objective of this study was to report the HRQOL of CAD patients under secondary prevention-related treatment and follow-up using the 36-Item Short Form (SF-36) tool.

Methods: This was an analytical cross-sectional survey done in a hospital/clinic setting. We recruited CAD patients 30 to 80 years old with 1 to 6 years of follow-up. Patients selfreported HRQOL using $\mathrm{SF}-36$.

Results: We recruited 1206 patients, among whom 879 (72.9\%) were male. The mean age of patients was $61.3(9.6)$ years. Mean ( \pm standard deviation) scores for physical functioning, role limitations due to physical health, pain, and general health were $66.48 \pm 29.41,78.96 \pm 28.01,80.96 \pm 21.15$, and $51.49 \pm 20.19$, respectively. The scores for role limitations due to emotional problems, energy/fatigue, emotional well-being, and social functioning were 76.62 $\pm 28.0,66.18 \pm$ $23.92,76.91 \pm 20.47$, and $74.49 \pm 23.55$. In subgroup analysis, age, sex, type of CAD, and treatment showed no significant association with any of the 8 domains of QOL. In addition, hypertension and diabetes showed no significant association with the individual domains of HRQOL.

Conclusion: Patients with coronary artery disease under secondary prevention-related treatment have suboptimal HRQOL under both physical and mental domains. The role

Received August 13, 2020; received in revised form October 1, 2020; accepted October 1, 2020.

Correspondence: Dr. Remya Sudevan, Departments of Health Sciences Research \& Cardiology, Amrita Institute of Medical Sciences and Research Centre, Kochi, Kerala, India 682041; 918301993172; fax: 914842802020 (e-mail: drremyasudevan27@gmail.com). of demographic factors, comorbidities, disease subtypes, and treatment options in modifying HRQOL among patients with CAD appears to be minimal.

\section{INTRODUCTION}

Noncommunicable diseases (NCDs) are known to impart a drastic and significant disease burden on low- and middleincome countries [Mahesh 2017; WHO 2017]. Among the NCDs, cardiovascular diseases (CVDs) account for the major proportion of mortality and morbidity globally [WHO 2017]. A shift of CVD burden from high-income to low- and middle-income countries (LMICs) has occurred in the last few decades [India 2017]. In India, ongoing demographic and epidemiological transitions have made this shift enormous [India 2017].

Traditionally, outcomes measured after cardiac events were predominantly classic clinical outcomes such as eventfree survival and overall survival after the index event [Leidl 2001]. In the last 2 decades, there has been a radical change in quantifying medical outcomes after CVD events [Weinstein 1996]. A complementary method in terms of health-related quality of life (HRQOL) was developed to measure the medical effectiveness of interventions from the patient perspective [Weinstein 1996]. Quality of life (QOL) represents the physical and mental status of a patient related to the living context in terms of their subjective perception [Mahesh 2017]. The physical and mental QOL of cardiac patients is generally not addressed as a part of their treatment [Bahall 2018].

HRQOL in patients with heart disease can be assessed using generic or disease-specific tools. The disease-specific tools, such as the Seattle Angina Questionnaire or the Mac New, focus on heart disease-related symptoms [Spertus 1995; Hofer 2004]. The generic questionnaires, such as EQ 5D and the 36-Item Short Form (SF-36), are nonspecific from a disease perspective and enable comparison of the HRQOL 
in cardiac patients with that of the general population or patients with other illnesses [Mahesh 2017; Weinstein 1996; Lee 2018]. Among the generic tools, SF-36 is the most popular for the measurement of QOL in patients after myocardial infarction (MI) [Mahesh 2017; Weinstein 1996; Bahall 2018; Lee 2018].

Previous studies have reported low HRQOL among patients with coronary artery disease (CAD) compared with the general population [Mollon 2017; Brown 1999]. A recent study reported that MI survivors experienced significantly lower HRQOL on domains of general health, physical health, daily activity, and mental health compared with propensity score-matched controls [Brown 1999]. There is very limited information related to HRQOL among patients with CAD from South Asia.

The growing importance of HRQOL in patients with heart disease makes it necessary to identify factors associated with impaired HRQOL in this population. Identification of such predictors of low HRQOL in those with CAD may help in risk stratification, adjusting the outcomes of interventions by identifying the associated factors for different treatments, generating inputs in costing of health models, and determining patient attributes regarding health [Schweikert 2009].

The primary objective of this study was to report the HRQOL of documented CAD patients under secondary prevention-related treatment using SF-36. The secondary objective was to examine the association of factors such as age; sex; place of residence; socioeconomic status (SES); insurance coverage; risk factors such as hypertension, diabetes, and dyslipidemia; type of CAD; and type of treatment with individual domains of HRQOL.

\section{METHODS}

The study was conducted in 2 tertiary care hospitals and 2 cardiology clinic-based practices, all situated in Ernakulam district, Kerala, India. The study was coordinated by Amrita Institute of Medical Sciences (Kochi, India). The duration of the study was 24 months (January 2017 to January 2019). The study design was an analytical cross-sectional survey.

We used the study by da Silva et al [2011] to calculate the sample size. The study reported mean \pm standard deviation (SD) of the 8 domains of SF-36. The minimum sample size required to estimate the mean for the individual domains of SF-36 with a $95 \%$ confidence interval (CI) and a precision of 2.5 units ranged from 218 to 1146 . We inflated the sample size to 1200 to adjust for withdrawals from the study.

We recruited patients with documented CAD who were under secondary prevention-related treatment and follow-up at the 4 institutions included in the study. For the purpose of this study, we defined CAD as per Sheridan and Crossman [2002].

The inclusion criteria were (1) documented CAD patients with a minimum follow-up period of 1 year since diagnosis at the time of enrollment, (2) age 30 to 80 years, (3) residing in Ernakulam district, and (4) who could comprehend English or Malayalam. The exclusion criteria were (1) those with a follow-up period of $>6$ years and (2) those with concomitant illnesses such as end-stage renal disease, chronic liver failure, malignancy, or stroke. We sequentially enrolled all patients from the 4 study institutions until the required sample size was achieved.

The study used a structured questionnaire to collect data regarding demographics, clinical history, type of CAD, and type of treatment. We used Kuppuswamy's socioeconomic scale (2018) for classifying the SES of the study participants [Saleem 2018]. The SES was later classified into low $(<10)$, middle (11 to 25), and high (26 to 29) using the scores derived from the same scale [Saleem 2018]. Additional details regarding the study methodology are available in an earlier publication [Sudevan 2020].

The Medical Outcomes SF-36 questionnaire was used to collect data regarding HRQOL [Busija 2011]. The 36-item scale contains 36 questions that measure 8 domains of health status: general health, physical functioning, role limitation due to physical health (RLDPH), pain, energy/fatigue, social functioning, role limitation due to emotional health (RLDEH), and mental health [Busija 2011; Lins 2016]. The recall period of SF-36 is 4 weeks. The SF-36 tool has been validated in India by earlier studies including populations with and without disease [Sinha 2013; Manavalan 2017; Shivaprasad 2018]. The tool is used globally to measure the QOL of post-MI patients and those with other medical conditions [Eriksson 2013; Höfer 2006; Beck 2001; Simpson 2005; Pilote 2002].

The English version of SF-36 was translated to Malayalam. The Malayalam version was then back-translated to English by 2 separate language experts. The original English version and the back-translated versions were compared, and necessary modifications were done to improve concurrence. The patients were interviewed in either English or Malayalam. All interviews were done by study personnel who were trained by the principal investigator before the commencement of data collection. Administration of the SF-36 was conducted in the hospital or clinic for enrolled patients. The SF-36 tool was taken by patients at the hospital or clinic.

\section{Statistical Analysis}

We characterized the population by computing frequencies and percentages of baseline variables. The distribution of SF-36 domains was explored by computing means and SDs, overall and by sex. We fitted separate multiple linear regression models to assess the association of each domain of SF-36 with the following risk factors: age, sex, place of residence, SES, insurance status, hypertension, diabetes, dyslipidemia, type of $\mathrm{CAD}$, and treatment. We performed graphical checks to evaluate the normality assumptions required for the validity of regression models. For each risk factor in the subgroup analysis, we computed the adjusted mean difference, presented the $95 \%$ CI, and reported the statistical significance with a cutoff of 0.005 to adjust for multiple comparisons. Data were analyzed using SAS version 9.4 (SAS Institute, Cary, NC).

\section{Ethical Approval}

The study was approved by the institutional ethics committee (IRB-AIMS-2017-125). We obtained written consent 
from all study participants after informing them about the study objectives and study process. The consent form included items such as title, purpose, methods, benefits, and right to withdraw from the study. The investigators ensured strict confidentiality during the study process.

\section{RESULTS}

\section{Baseline Data}

We approached a total of 1230 CAD patients under secondary prevention treatment who satisfied the inclusion and exclusion criteria. Among them, 1206 (98\%) provided informed consent and participated in the data collection process. All recruited patients were under follow-up after the primary event/diagnosis from the 4 study centers. The baseline details related to the study population are presented in Table 1.

In the study population, 879 (72.9\%) were male, $767(63.6 \%)$ reported to be residing in rural areas, 647 (53.6\%) were 61 to 80 years old, $537(44.5 \%)$ were 41 to 60 years old, and $22(1.8 \%)$ were 30 to 40 years old. The mean age of males and females were $60.4+9.6$ and $63.5+9.3$ years respectively. The age at diagnosis of CAD or occurrence of primary event was $58.6 \pm 9.6$ years. The median follow-up reported by the study population was 2.6 years (interquartile range $1.5,4.4$ years).

A total of 436 patients (36.2\%) reported having some form of insurance coverage, and 497 (41.2\%) reported having a family history of CAD. The corresponding numbers for hypertension, diabetes, and dyslipidemia were 637 (52.8\%), $609(50.5 \%)$, and $544(45.1 \%)$. At the time of interview, 28 patients $(2.3 \%)$ reported to be smokers, and $93(7.7 \%)$ reported consumption of alcohol. Regarding diagnosis, 379 (31.4\%) reported ST elevation myocardial infarction (STEMI), 285 $(23.6 \%)$ reported non-ST elevation myocardial infarction (NSTEMI), 258 (21.4\%) reported unstable angina, and 284 (23.5\%) reported effort angina. Regarding treatment, 357 patients $(29.7 \%)$ reported to be on medical therapy only, 679 $(56.3 \%)$ reported angioplasty, and $170(14.1 \%)$ reported coronary artery bypass graft (CABG).

\section{Distribution of SF-36 Domains}

The SF-36 has 4 domains categorized under physical components: physical functioning, RLDPH, pain, and general health. The overall means reported were $66.48 \pm 29.41,78.96$ $\pm 28.01,80.96 \pm 21.15$, and $51.49 \pm 20.19$, respectively. The sex-stratified values for the 4 domains are presented in Table 2. The remaining 4 domains-RLDEH, energy/fatigue, emotional well-being, and social functioning - are grouped under the mental components. The corresponding means of these domains were $76.62 \pm 28.0,66.18 \pm 23.92,76.91 \pm 20.47$, and $74.49 \pm 23.55$. The sex-stratified values for these 4 domains are presented in Table 2 .

\section{Subgroup Comparison of Physical Components}

We did a subgroup analysis to examine the association of physical functioning, RLDPH, pain, and general health with the probable confounders listed above. Age, sex, insurance status, type of $\mathrm{CAD}$, and type of treatment showed no
Table 1. Baseline characteristics of the study population*

\begin{tabular}{|c|c|c|c|}
\hline Variable & All & Male & Female \\
\hline$n$ & $1206(100)$ & $879(72.9)$ & $327(27.1)$ \\
\hline \multicolumn{4}{|l|}{ Place of residence } \\
\hline Urban & 439 (36.4) & $313(35.6)$ & $126(38.5)$ \\
\hline Rural & $767(63.6)$ & $566(64.4)$ & $201(61.5)$ \\
\hline \multicolumn{4}{|l|}{ SES } \\
\hline High & $44(3.6)$ & $37(4.2)$ & $7(2.1)$ \\
\hline Middle & $742(61.5)$ & $582(66.2)$ & $160(48.9)$ \\
\hline Low & $420(34.8)$ & $260(29.6)$ & $160(48.9)$ \\
\hline \multicolumn{4}{|l|}{ Insurance } \\
\hline Yes & $436(36.2)$ & $313(35.6)$ & $123(37.8)$ \\
\hline \multicolumn{4}{|l|}{ Comorbidities } \\
\hline Family history of $C A D$ & $497(41.2)$ & $356(40.5)$ & $141(43.1)$ \\
\hline Hypertension & $637(52.8)$ & $427(48.6)$ & $210(64.2)$ \\
\hline Diabetes & $609(50.5)$ & $432(49.1)$ & $177(54.1)$ \\
\hline Dyslipidemia & $544(45.1)$ & $374(42.6)$ & $170(52)$ \\
\hline Smoking & $28(2.3)$ & $28(3.2)$ & 0 \\
\hline Alcohol intake & $93(7.7)$ & $84(9.6)$ & $9(2.8)$ \\
\hline \multicolumn{4}{|l|}{ CAD subtype } \\
\hline STEMI & 379 (31.4) & $285(32.4)$ & $94(28.7)$ \\
\hline NSTEMI & $285(23.6)$ & $210(23.9)$ & $75(22.9)$ \\
\hline Unstable angina & $258(21.4)$ & $192(21.8)$ & $66(20.2)$ \\
\hline Effort angina & $284(23.5)$ & $192(21.8)$ & $92(28.1)$ \\
\hline \multicolumn{4}{|l|}{ Treatment } \\
\hline Medical therapy alone & $357(29.7)$ & $211(24.1)$ & $146(44.8)$ \\
\hline Angioplasty & $679(56.3)$ & $527(60.1)$ & $152(46.6)$ \\
\hline CABG & $170(14.1)$ & $141(16.0)$ & $29(8.9)$ \\
\hline
\end{tabular}

*Data are $\mathrm{n}(\%)$.

Table 2. Distribution of SF-36 domains: overall and sex-stratified profile*

\begin{tabular}{llll}
\hline Variable & Overall & Male & Female \\
\hline Physical functioning & $66.48(29.41)$ & $68.72(29.76)$ & $66.48(28.37)$ \\
RLDPH & $78.96(28.01)$ & $81.65(28.23)$ & $78.96(27.27)$ \\
RLDEP & $76.62(28.00)$ & $78.59(28.09)$ & $76.62(27.70)$ \\
Energy/fatigue & $66.18(23.92)$ & $68.46(24.28)$ & $66.18(22.79)$ \\
Emotional well-being & $76.91(20.47)$ & $78.24(21.02)$ & $76.91(18.87)$ \\
Social functioning & $74.49(23.55)$ & $75.34(23.34)$ & $74.49(24.11)$ \\
Pain & $80.96(21.15)$ & $81.26(21.42)$ & $80.96(20.42)$ \\
General health & $51.49(20.19)$ & $50.32(20.16)$ & $51.49(20.26)$ \\
\hline
\end{tabular}

*Data are $\mathrm{n}(\%)$. 
Table 3. Subgroup comparison of physical components of SF-36*

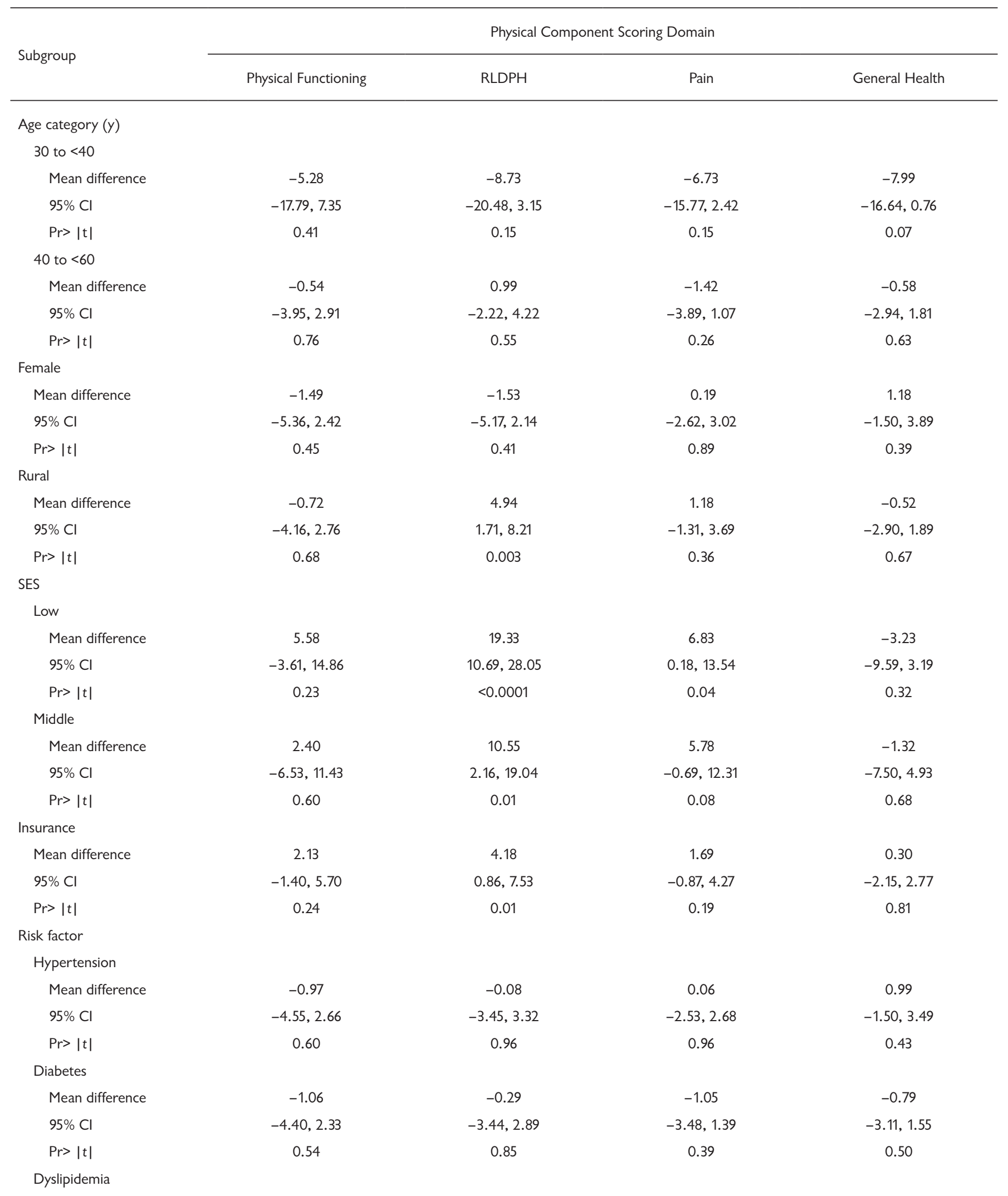




\begin{tabular}{|c|c|c|c|c|}
\hline Mean difference & -7.2 & -3.62 & -4.20 & -3.45 \\
\hline $95 \% \mathrm{Cl}$ & $-10.83,-3.53$ & $-7.03,-0.17$ & $-6.83,-1.55$ & $-5.97,-0.91$ \\
\hline $\operatorname{Pr}>|t|$ & 0.0001 & 0.04 & 0.0018 & 0.007 \\
\hline \multicolumn{5}{|l|}{ CAD type } \\
\hline \multicolumn{5}{|l|}{ Effort angina } \\
\hline Mean difference & 1.92 & 3.60 & -1.81 & -0.79 \\
\hline $95 \% \mathrm{Cl}$ & $-3.09,6.99$ & $-1.11,8.36$ & $-5.44,1.85$ & $-4.25,2.72$ \\
\hline $\operatorname{Pr}>|t|$ & 0.45 & 0.13 & 0.33 & 0.66 \\
\hline \multicolumn{5}{|l|}{ NSTEMI } \\
\hline Mean difference & 2.66 & 0.80 & -0.45 & 0.75 \\
\hline $95 \% \mathrm{Cl}$ & $-2.30,7.67$ & $-3.86,5.50$ & $-4.04,3.17$ & $-2.68,4.22$ \\
\hline $\operatorname{Pr}>|t|$ & 0.29 & 0.74 & 0.80 & 0.66 \\
\hline \multicolumn{5}{|l|}{ STEMI } \\
\hline Mean difference & 3.71 & 2.48 & 0.18 & 0.57 \\
\hline $95 \% \mathrm{Cl}$ & $-0.95,8.42$ & $-1.90,6.91$ & $-3.19,3.59$ & $-2.66,3.83$ \\
\hline $\operatorname{Pr}>|t|$ & 0.12 & 0.23 & 0.91 & 0.73 \\
\hline \multicolumn{5}{|l|}{ Treatment } \\
\hline \multicolumn{5}{|l|}{ Angioplasty } \\
\hline Mean difference & 1.07 & 0.74 & 1.94 & 1.35 \\
\hline $95 \% \mathrm{Cl}$ & $-2.79,4.97$ & $-2.89,4.40$ & $-0.86,4.76$ & $-1.32,4.05$ \\
\hline $\operatorname{Pr}>|t|$ & 0.59 & 0.69 & 0.17 & 0.32 \\
\hline \multicolumn{5}{|l|}{ CABG } \\
\hline Mean difference & -2.53 & 0.50 & -0.21 & 1.09 \\
\hline $95 \% \mathrm{Cl}$ & $-8.04,3.03$ & $-4.68,5.72$ & $-4.20,3.81$ & $-2.72,4.94$ \\
\hline $\operatorname{Pr}>|t|$ & 0.37 & 0.85 & 0.92 & 0.58 \\
\hline
\end{tabular}

significant association with any of the 4 physical domains of QOL. In addition, hypertension and diabetes showed no significant association with the physical domains.

The RLDPH domain showed significant associations with place of residence and SES. Compared with patients from urban areas, those from rural areas showed higher values for RLDPH (adjusted mean difference 4.94; $P=.003$ ). Patients from the low SES group showed higher values for RLDPH compared with the high SES group (adjusted mean difference 19.33; $P<.0001)$.

Both physical functioning and pain showed an association with dyslipidemia. Those without dyslipidemia reported lower physical functioning (adjusted mean difference $-7.2 ; P$ $=.0001)$ versus those with dyslipidemia. Similarly, those without dyslipidemia reported lower pain (adjusted mean difference $-4.20 ; P=.0018$ ) versus those with dyslipidemia. The details of subgroup comparison of physical components are presented in Table 3 .

\section{Subgroup Comparison of Mental Components}

We examined the association of mental component domains with age, sex, place of residence, SES, insurance, risk factors, type of CAD, and type of treatment. Age, sex, type of $\mathrm{CAD}$, and type of treatment showed no significant association with any of the 4 mental domains of QOL. In addition, hypertension and diabetes showed no significant association with the mental domains.

The domain role RLDEP showed a significant association with SES and insurance. Compared with the high SES group, the low SES group showed a higher value for RLDEP (adjusted mean difference $14.62 ; P=.001)$. Similarly, those with insurance reported higher values for RLDEP compared with those who reported no insurance (adjusted mean difference 5.24; $P=.002$ ). The social functioning domain showed a significant association with dyslipidemia. Those without dyslipidemia reported lower social functioning versus those with dyslipidemia (adjusted mean difference $-6.01 ; P<.0001)$. The subgroup comparison of mental components is represented in Table 4.

\section{DISCUSSION}

This is the first large study from South Asia that looked at HRQOL of patients with documented CAD who were under 
Table 4. Subgroup comparison of mental components of SF-36*

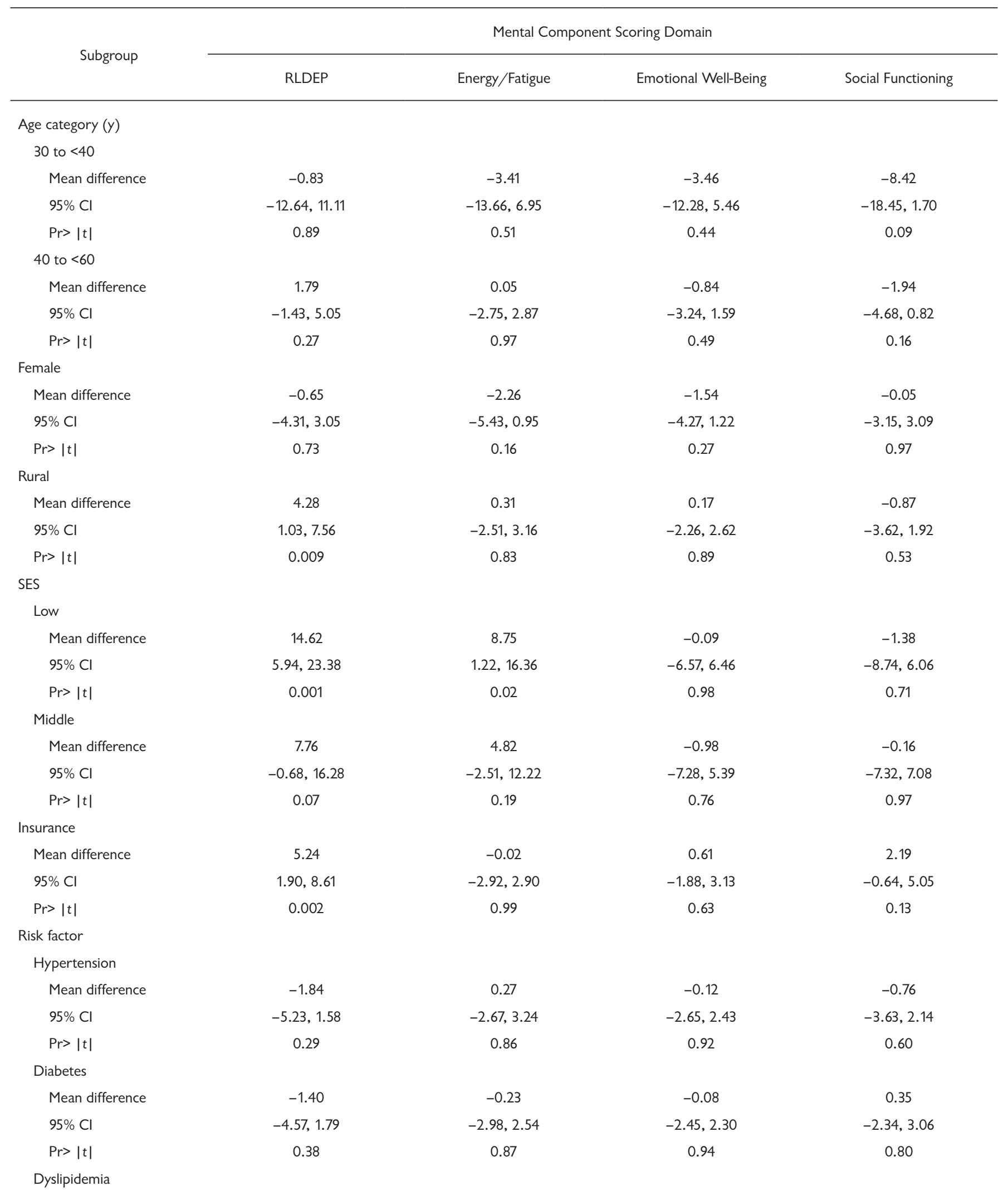




\begin{tabular}{|c|c|c|c|c|}
\hline Mean difference & -3.36 & -2.59 & -1.77 & -6.01 \\
\hline $95 \% \mathrm{Cl}$ & $-6.79,0.11$ & $-5.57,0.42$ & $-4.33,0.82$ & $-8.92,-3.07$ \\
\hline $\operatorname{Pr}>|t|$ & 0.05 & 0.09 & 0.18 & $<0.0001$ \\
\hline \multicolumn{5}{|l|}{ Type of CAD } \\
\hline \multicolumn{5}{|l|}{ Effort angina } \\
\hline Mean difference & 3.02 & -1.49 & 1.38 & 2.32 \\
\hline $95 \% \mathrm{Cl}$ & $-1.71,7.81$ & $-5.60,2.66$ & $-2.15,4.95$ & $-1.70,6.37$ \\
\hline $\operatorname{Pr}>|t|$ & 0.21 & 0.48 & 0.44 & 0.26 \\
\hline \multicolumn{5}{|l|}{ NSTEMI } \\
\hline Mean difference & 1.27 & 1.37 & 1.99 & 3.48 \\
\hline $95 \% \mathrm{Cl}$ & $-3.41,6.00$ & $-2.70,5.47$ & $-1.51,5.52$ & $-0.49,7.49$ \\
\hline $\operatorname{Pr}>|t|$ & 0.59 & 0.51 & 0.26 & 0.09 \\
\hline \multicolumn{5}{|l|}{ STEMI } \\
\hline Mean difference & 0.48 & -0.47 & 1.49 & 2.51 \\
\hline $95 \% \mathrm{Cl}$ & $-3.92,4.93$ & $-4.29,3.39$ & $-1.79,4.82$ & $-1.23,6.28$ \\
\hline $\operatorname{Pr}>|t|$ & 0.83 & 0.81 & 0.37 & 0.19 \\
\hline \multicolumn{5}{|l|}{ Treatment } \\
\hline \multicolumn{5}{|l|}{ Angioplasty } \\
\hline Mean difference & 0.86 & 0.51 & 0.81 & -1.28 \\
\hline $95 \% \mathrm{Cl}$ & $-2.78,4.54$ & $-2.66,3.70$ & $-1.91,3.56$ & $-4.38,1.84$ \\
\hline $\operatorname{Pr}>|t|$ & 0.64 & 0.75 & 0.56 & 0.42 \\
\hline \multicolumn{5}{|l|}{ CABG } \\
\hline Mean difference & -0.74 & -0.79 & 0.30 & -3.43 \\
\hline $95 \% \mathrm{Cl}$ & $-5.94,4.52$ & $-5.30,3.77$ & $-3.59,4.22$ & $-7.84,1.03$ \\
\hline $\operatorname{Pr}>|t|$ & 0.78 & 0.73 & 0.88 & 0.13 \\
\hline
\end{tabular}

secondary prevention-related treatment and follow-up. The current study is probably the first that covered all major subtypes of CAD patients. The sample also represents patients under medical management, angioplasty, and CABG. Among the individual HRQOL domains, the maximum value was seen for pain and the minimum for general health.

In the subgroup analysis, 6 variables-age, sex, hypertension, diabetes, type of CAD, and type of treatment-showed no association with any of the 8 domains of SF-36. Among the subgroup variables, dyslipidemia showed the maximum association and was associated with 3 domains: physical functioning, pain, and social functioning. SES showed an association with 2 domains: RLDPH and RLDEP. The place of domicile and insurance status showed an association with 1 domain each, RLDPH and RLDEP, respectively.

A comparison between the current study results and that of a small study from India among community-dwelling disease-free individuals suggests that the predominant deficiencies come under the domains of physical functioning (93.59 versus 66.48), general health (79.41 versus 51.49$)$, social functioning (90.42 versus 74.4) , and emotional well-being (86.16 versus 76.91) [Sinha 2013].
HRQOL in CAD is probably influenced by several factors. Norris et al [2010] reported that age, sex, physical limitation, coronary anatomy, ejection fraction, and angina frequency together accounted for more than half of the variations in HRQOL among patients with CAD. In the current study, demographic factors such as age and sex did not show an independent role in modifying the HRQOL of CAD patients. The Pro-active Heart Trial examined the HRQOL among survivors of MI at 6 months' follow-up and reported a mixed association [Hawkes 2013]. Older CAD patients (>60 years) reported lower physical HRQOL $(-4.9,95 \%$ CI -7.6, -2.2) and higher mental HRQOL $(2.8,95 \%$ CI $0.7,4.9)$ compared with their younger counterparts [Hawkes 2013]. Schweikert et al [2009] reported that HRQOL differences between CAD patients and the general population was highest in the lower age groups. In the highest age group, there was no significant difference in HRQOL between CAD patients and their general counterparts [da Silva 2011]. The differences in study populations, tools, and analytical approaches may be the reasons for the different associations reported by the 3 studies.

The evidence related to the association of sex with HRQOL among patients with CAD gives mixed signals. Several studies 
have reported lower HRQOL values for women with CAD compared with their male counterparts [Schweikert 2009; Norris 2010; Martin 2012; Gijsberts 2015]. Martin et al [2012] reported lower HRQOL values for women with a history of CABG compared with men. The sex-based differences for individual domains were smaller and within a range of 2.03 to 3.71 units. The lack of sex-based difference in the current study, in contrast with Martin et al [2012], could be due to longer duration of follow-up (6 months versus 2 years) and the inclusion of all types of CAD.

The MONICA/KORA registry reported an adjusted HRQOL deficiency of 3.29 units for women MI survivors compared with their male counterparts as assessed by the EQ VAS at a mean follow-up of 9 years [Schweikert 2009]. The sex-based difference was predominantly contributed by patients in the older age strata ( $>65$ years) [Schweikert 2009]. The German cohort [Schweikert 2009] is older, with a mean age of $68.0 \pm 9.6$ years, than that of the current study (mean age of $61.3 \pm 9.6$ years).

Among the sociodemographic factors, only SES showed an association with HRQOL among CAD patients. This association was seen for 2 domains: RLDPH and RLDEP. Surprisingly, CAD patients hailing from the low socioeconomic levels exhibited significantly higher values for both domains in comparison with those from high SES levels.

In this study, both diabetes and hypertension failed to show an independent role in modifying the HRQOL of CAD patients. The lack of any significant association in the adjusted analysis was seen for all 8 domains of SF-36. Dyslipidemia was the only risk factor that showed an association with HRQOL: patients with dyslipidemia had a significant positive association with 3 of the 8 domains of SF-36.

Several studies have examined the association between diabetic status and HRQOL among patients with CAD under treatment and follow-up [Schweikert 2009; Martin 2012; Lindsay 2000]. Martin et al [2012] reported significant deficiencies for 4 of 8 HRQOL domains among CAD patients with diabetes who underwent CABG compared with their nondiabetic counterparts. The deficiencies at a follow-up of 6 months were small and ranged from -1.91 to -3.20 units [Martin 2012]. In contrast, Rumsfeld et al [2003] reported no association between diabetic status and HRQOL separately for patients with medically refractive angina who underwent either percutaneous coronary intervention (PCI) or CABG. The differences in study sample selection, duration of followup, and analytical approach may be reasons for the different results seen in the 3 studies.

The current study reported higher HRQOL among those CAD patients who were insured compared with their noninsured counterparts. This association was weak and was restricted to only 1 domain of SF-36 (RLDEP).

The association between HRQOL and type of treatment for CAD was examined by several studies in the past [Spertus 1995; Rumsfeld 2003; van Domburg 2008; Zhang 2003; Spertus 2005; Cohen 2011; Weintraub 2008]. Domberg et al [2008] reported that among CAD patients who were assessed at 36 months' follow-up, there was no significant differences in HRQOL between PCI and CABG arms. Rumsfeld et al [2003] reported that in patients with medically refractive angina, none of the HRQOL domains showed significant differences between CABG and PCI arms when assessed at 6 months' follow-up. Similarly, Zhang et al [2003] reported that QOL was comparable between those treated with PCI versus those with CABG at 12 months' follow up. Results from the current study as well as the majority of those reported above suggest a lack of association between HRQOL and type of treatment in CAD patients.

\section{Strengths and Limitations}

The strengths of this study are a large sample size, availability of sociodemographic data, inclusion of all major categories of $\mathrm{CAD}$, information on various types of treatment, and adjusted analysis to minimize confounding. The limitations include lack of geographic/ethnic variability and nonavailability of details related to depression.

\section{Conclusion}

Coronary artery disease patients under secondary prevention-related treatment have suboptimal HRQOL under both physical and mental domains. Comparison with earlier studies suggests marked heterogeneity and limited roles for factors such as age, sex, diabetes, hypertension, and type of treatment in modifying the HRQOL among patients with CAD under treatment. This also suggests that the major drivers of HRQOL among patients with CAD under treatment are yet to be identified. Future studies should focus on identifying such factors. Treatment protocols as well as interventions targeting improvements in outcomes for CAD patients should consider documentation and regular monitoring of HRQOL.

\section{ACKNOWLEDGMENTS}

Dr. Ancy Paul, Dr. Riya Kuriakose, Mr. Vishnu Sugathan, Mr. Vishak, Mrs. K.S. Sonu, Mrs. Neethu Raj, and Dr. Apsy Varky are acknowledged for data collection and patient care.

\section{REFERENCES}

Bahall M and Khan K. Quality of life of patients with first-time AMI: A descriptive study. Health Qual Life Outcomes 2018;16:32.

Beck CA, Joseph L, Bélisle P, Pilote L; QOLAMI Investigators. Predictors of quality of life 6 months and 1 year after acute myocardial infarction. Am Heart J 2001;142:271-279.

Brown N, Melville M, Gray D, et al. Quality of life four years after acute myocardial infarction: Short Form 36 scores compared with a normal population. Heart 1999;81:352-358.

Busija L, Pausenberger E, Haines TP, Haymes S, Buchbinder R, Osborne RH. Adult measures of general health and health-related quality of life: Medical Outcomes Study Short Form 36-Item (SF-36) and Short Form 12-Item (SF-12) Health Surveys, Nottingham Health Profile (NHP), Sickness Impact Profile (SIP), Medical Outcomes Study Short Form 6D (SF-6D), Health Utilities Index Mark 3 (HUI3), Quality of Well-Being Scale (QWB), and Assessment of Quality of Life (AQoL). Arthritis Care Res (Hoboken) 2011;63(suppl 11):S383-S412.

Cohen DJ, Van Hout B, Serruys PW, et al. Quality of life after PCI with 
drug-eluting stents or coronary-artery bypass surgery. N Engl J Med 2011;364:1016-1026.

da Silva SA, Passos SR, Carballo MT, Figueiró M. Quality of life assessment after acute coronary syndrome: Systematic review. Arq Bras Cardiol 2011;97:526-540

Eriksson M, Asplund K, Hochwälder J, Svedlund M. Changes in hope and health-related quality of life in couples following acute myocardial infarction: A quantitative longitudinal study. Scand J Caring Sci 2013;27:295-302.

Gijsberts CM, Agostoni P, Hoefer IE, et al. Gender differences in healthrelated quality of life in patients undergoing coronary angiography. Open Heart 2015;2:e000231.

Hawkes AL, Patrao TA, Ware R, Atherton JJ, Taylor CB, Oldenburg BF. Predictors of physical and mental health-related quality of life outcomes among myocardial infarction patients. BMC Cardiovasc Disord 2013;13:69

Höfer S, Lim L, Guyatt G, Oldridge N. The MacNew Heart Disease health-related quality of life instrument: A summary. Health Qual Life Outcomes 2004;2:3.

Höfer S, Doering S, Rumpold G, Oldridge N, Benzer W. Determinants of health-related quality of life in patients with coronary artery disease. Eur J Cardiovasc Prev Rehabil 2006;13:398-406.

India State-Level Disease Burden Initiative Collaborators. Nations within a nation: Variations in epidemiological transition across the states of India, 1990-2016 in the Global Burden of Disease Study. Lancet 2017;390:2437-2460

Lee YM, Kim RB, Lee HJ, Kim K et al. Relationships among medication adherence, lifestyle modification, and health-related quality of life in patients with acute myocardial infarction: A cross-sectional study. Health Qual Life Outcomes 2018;16:100.

Leidl R, Sintonen H, Abbühl B, Hoffmann C, von der Schulenburg J, König H. Do physicians accept quality of life and utility measurement? An Austrian, Finnish, and German survey. Eur J Health Econ 2001;2:170-175.

Lindsay GM, Hanlon P, Smith LN, Wheatley DJ. Assessment of changes in general health status using the short-form 36 questionnaire 1 year following coronary artery bypass grafting. Eur J Cardiothorac Surg 2000;18:557-564.

Lins L, Carvalho FM. SF-36 total score as a single measure of health-related quality of life: Scoping review. SAGE Open Med 2016;4:2050312116671725

Mahesh PKB, Gunathunga MW, Jayasinghe S, Arnold SM, Haniffa R, De Silva AP. Pre-event quality of life and its influence on the post-event quality of life among patients with ST elevation and non-ST elevation myocardial infarctions of a premier province of Sri Lanka. Health Qual Life Outcomes 2017;15:154

Manavalan M, Majumdar A, Harichandra Kumar K T, Priyamvada PS. Assessment of health-related quality of life and its determinants in patients with chronic kidney disease. Indian J Nephrol 2017;27:37-43.

Martin LM, Holmes SD, Henry LL, et al. Health-related quality of life after coronary artery bypass grafting surgery and the role of gender. Cardiovasc Revasc Med 2012;13:321-327.

Mollon L, Bhattacharjee S. Health related quality of life among myocardial infarction survivors in the United States: A propensity score matched analysis. Health Qual Life Outcomes 2017;15:235.

Norris CM, Murray JW, Triplett LS, Hegadoren KM. Gender roles in persistent sex differences in health-related quality of life outcomes of patients with coronary artery disease. Gend Med 2010;7:330-339.

Pilote L, Lauzon C, Huynh T, et al. Quality of life after acute myocardial infarction among patients treated at sites with and without on-site availability of angiography. Arch Intern Med 2002;162:553-559.

Rumsfeld JS, Magid DJ, Plomondon ME, et al. Health-related quality of life after percutaneous coronary intervention versus coronary bypass surgery in high-risk patients with medically refractory ischemia. J Am Coll Cardiol 2003;41:1732-1738.

Saleem SM. Modified Kuppuswamy scale updated for year 2018. Indian J Res 2018;7:6-7.

Schweikert B, Hunger M, Meisinger C, König HH, Gapp O, Holle R. Quality of life several years after myocardial infarction: Comparing the MONICA/KORA registry to the general population. Eur Heart J 2009;30:436-443.

Sheridan PJ, Crossman DC. Critical review of unstable angina and non-ST elevation myocardial infarction. Postgrad Med J 2002;78:717-726.

Shivaprasad C, Rakesh B, Anish K, Annie P, Amit G, Dwarakanath CS. Impairment of health-related quality of life among Indian patients with hypothyroidism. Indian J Endocr Metab 2018;22:335-338.

Simpson E, Pilote L. Quality of life after acute myocardial infarction: A comparison of diabetic versus non-diabetic acute myocardial infarction patients in Quebec acute care hospitals. Health Qual Life Outcomes 2005;3:80.

Sinha R, van den Heuvel WJ, Arokiasamy P. Validity and reliability of MOS Short Form Health Survey (SF-36) for use in India. Indian J Commun Med 2013;38:22-26.

Spertus JA, Winder JA, Dewhurst TA, Deyo RA, Prodzinski J, McDonell M,Fihn SD. Development and evaluation of the Seattle Angina Questionnaire: A new functional status measure for coronary artery disease. J Am Coll Cardiol 1995;25:333-341.

Spertus JA, Nerella R, Kettlekamp R, et al. Risk of restenosis and health status outcomes for patients undergoing percutaneous coronary intervention versus coronary artery bypass graft surgery. Circulation 2005; 111:768-773.

Sudevan R, Vasudevan D, Raj M, et al. Compliance to secondary prevention strategies for coronary artery disease: a hospital-based cross-sectional survey from Ernakulam, South India. BMJ Open 2020;10:e037618.

van Domburg RT, Daemen J, Pedersen SS, et al. Short- and long- term health related quality-of-life and anginal status after randomisation to coronary stenting versus bypass surgery for the treatment of multivessel disease: Results of the Arterial Revascularisation Therapy Study (ARTS). EuroIntervention 2008;3:506-511.

Weinstein MC, Siegel JE, Gold MR, Kamlet MS, Russell LB. Recommendations of the Panel on Cost-effectiveness in Health and Medicine. JAMA 1996;276:1253-1258.

Weintraub WS, Spertus JA, Kolm P, et al. Effect of PCI on quality of life in patients with stable coronary disease. N Engl J Med 2008;359:677-687.

World Health Organization; 2017. Available at: https://www.who.int/ news-room/fact-sheets/detail/cardiovascular-diseases-(cvds) (Accessed November 9, 2020).

Zhang Z, Mahoney EM, Stables RH, et al. Disease-specific health status after stent-assisted percutaneous coronary intervention and coronary artery bypass surgery: One-year results from the Stent or Surgery trial. Circulation 2003;108:1694-1700. 